\title{
Расширение уровня информативности метода термогазовой хроматографии
}

\section{(по результатам экспериментальных работ на керне Ен-Яхинской сверхглубокой скважины СГ-7)}

\section{М. М. Белова \\ ОАО «Камский научно-исследовательский институт комплексных иссле- дований глубоких и сверхглубоких скважин», 614016, Пермь, ул. Красно- флотская, 15. E-mail: Kamniikigs@inbox.ru; info@ niikigs.ru \\ (Статья поступила в редакцию 29 ноября 2013 г.)}

Рассмотрены результаты исследований глубокосорбированных газов, полученные в ходе выполнения экспериментальной работы. Анализы газов выполнены с использованием образцов пород Ен-Яхинской скважины методом термогазовой хроматографии (ТГХ) при трёх температурах: $90,200,300^{\circ} \mathrm{C}$. Обобщение результатов позволило сделать выводы о том, что метод ТГХ можно использовать для уточнения разных сторон и особенностей процесса генерации газов.

Ключевые слова: метод термогазовой хроматографии, глубокосорбированные газы, катагенез, термодеструкиия, органическое вещество.

Исследования газов пород проводились методом термогазовой хроматографии (ТГХ), который основан на изучении газов, извлекаемых из измельченной породы при кратковременном нагревании до $200^{\circ} \mathrm{C}$. Согласно методике, именно при этой температуре извлекаются газы, свойственные самой породе. Количество деструкционных углеводородов (УВ) мало и не оказывает существенного влияния на выход газов. Методика исследования направлена на выявление полей аномальных концентраций УВ в разрезах скважины и по площадям опробования.

Объектами эксперимента стали 7 образцов пород Ен-Яхинской скважины, отобранные в широком диапазоне глубин 3000-7000 м и в большом интервале катагенетической преобразованности органического вещества стадий $\mathrm{MK}_{2}-$ $\mathrm{AK}_{3}$ (табл. 1).

(C) Белова М. М., 2014
Анализы были выполнены при трёх температурах: 90, 200, 300ㄷ. Выбор температур не случаен: приборы типа Rock-Eval при $90^{\circ} \mathrm{C}$ определяют параметр $\mathrm{S}_{0}$ (содержание газовых компонентов в породе); при $\mathrm{T}=200^{\circ} \mathrm{C}$ работает метод ТГХ. $300^{\circ} \mathrm{C}$ были выбраны для отслеживания процессов воздействия на породу более высокой температуры.

Результаты анализов представлены на диаграммах. Для корректного сравнения результатов выбраны нормированные показатели: отношение метана, суммы предельных УВ и суммы непредельных УВ к Сорг.

Эксперимент показал, что при $\mathrm{T}=90^{\circ} \mathrm{C}$ количество извлекаемых газов очень мало, так как выделяются только слабосвязанные газы. Более ярко и наглядно состав газа виден при нагревании породы до $200^{\circ} \mathrm{C}$, при этом наряду со слабосвязанными выделяются и глубокосорбированные газы. На рис. 1 просматривается сходство качественного состава газа при 90 и $200^{\circ} \mathrm{C}$. 

Таблица 1. Характеристика образцов керна

\begin{tabular}{|c|c|c|c|c|c|}
\hline $\begin{array}{c}\text { Глубина } \\
\text { отбора, }\end{array}$ & $\begin{array}{c}\text { № об- } \\
\text { разца }\end{array}$ & Порода & $\begin{array}{c}\text { Стратиграфическое } \\
\text { положение }\end{array}$ & $\begin{array}{c}\text { Сорг, } \\
\text { \% }\end{array}$ & $\begin{array}{c}\text { Стадия } \\
\text { катагенеза }\end{array}$ \\
\hline 3624,1 & 16 & Аргиллит & Ачимовская толща & 0,49 & $\mathrm{MK}_{2}$ \\
\hline 3628,74 & 50 & Алевролит & Ачимовская толща & 0,42 & $\mathrm{MK}_{2}$ \\
\hline 3969,62 & 414 & У глистый аргиллит & Тюменская свита & 9,75 & $\mathrm{MK}_{2}$ \\
\hline 3975,89 & 458 & Аргиллит с углем & Тюменская свита & 11,47 & $\mathrm{MK}_{2}$ \\
\hline 5989,12 & $1926 П$ & $\begin{array}{c}\text { Песчаник с угли- } \\
\text { стыми включениями }\end{array}$ & $\begin{array}{c}\text { Варенгаяхинская сви- } \\
\text { та }\end{array}$ & 0,07 & $\mathrm{AK}_{2}$ \\
\hline 5990,97 & $1935-$ н & Аргиллит & $\begin{array}{c}\text { Варенгаяхинская сви- } \\
\text { та }\end{array}$ & 0,08 & $\mathrm{AК}_{2}$ \\
\hline 6933,08 & $3187 П$ & Базальт & Коротчаевская свита & 0,47 & $\mathrm{AK}_{3}$ \\
\hline
\end{tabular}

Дальнейшее нагревание породы привело к резкому увеличению значений всех соотношений, а именно метана, предельных и в особенности непре-
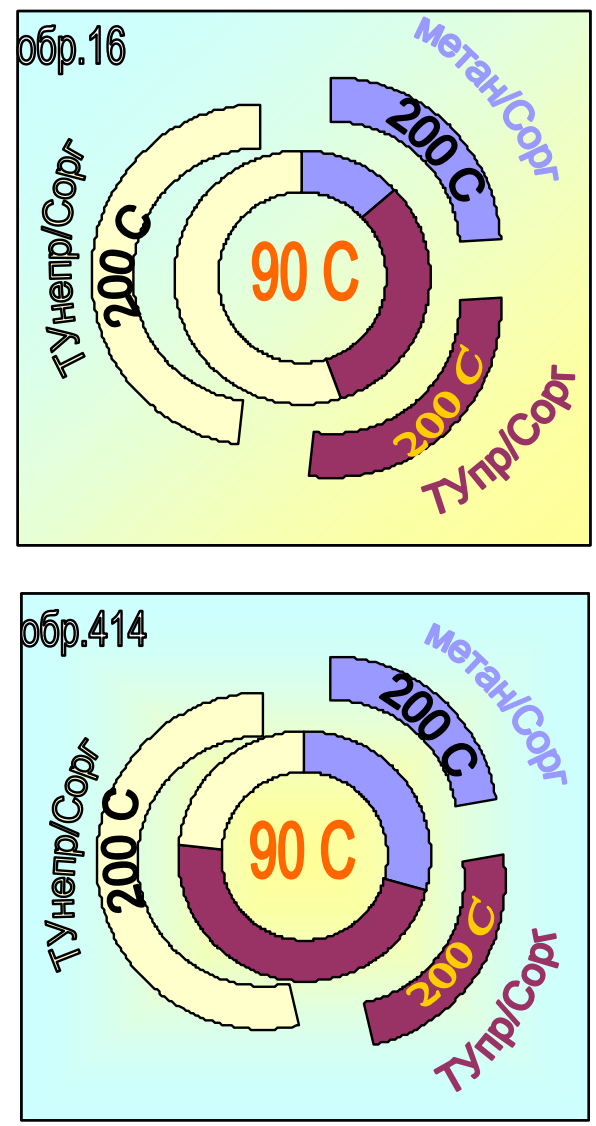

дельных УВ к Сорг, что говорит об активном протекании процесса термодеструкции OB и существенно искажает первичный состав выделившихся газов (рис. 2).
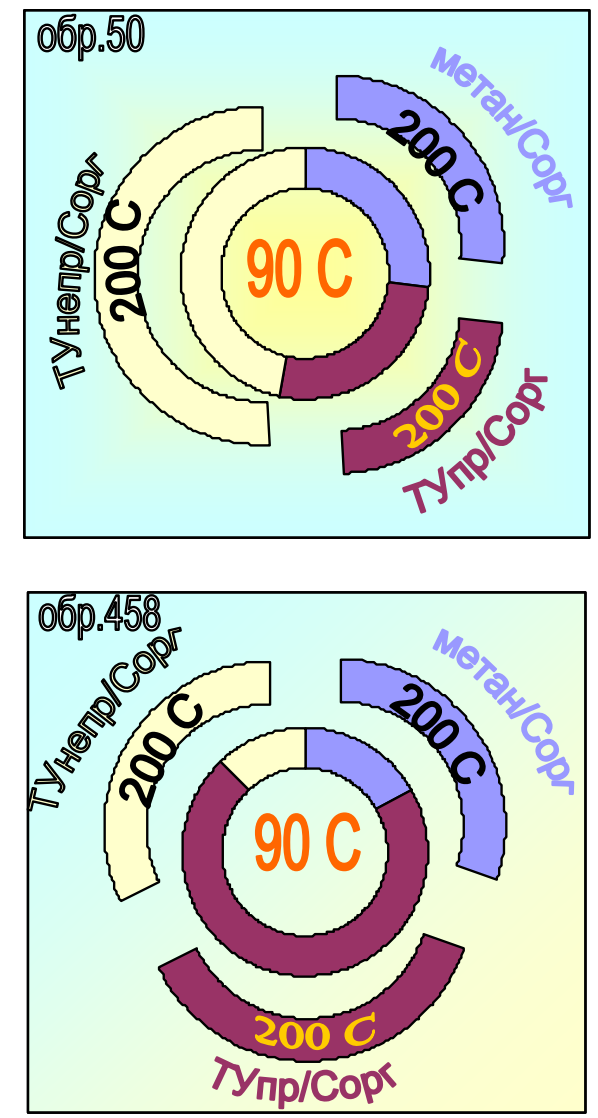

Рис. 1. Показатели состава газа при 90 и $200^{\circ} \mathrm{C}$ 

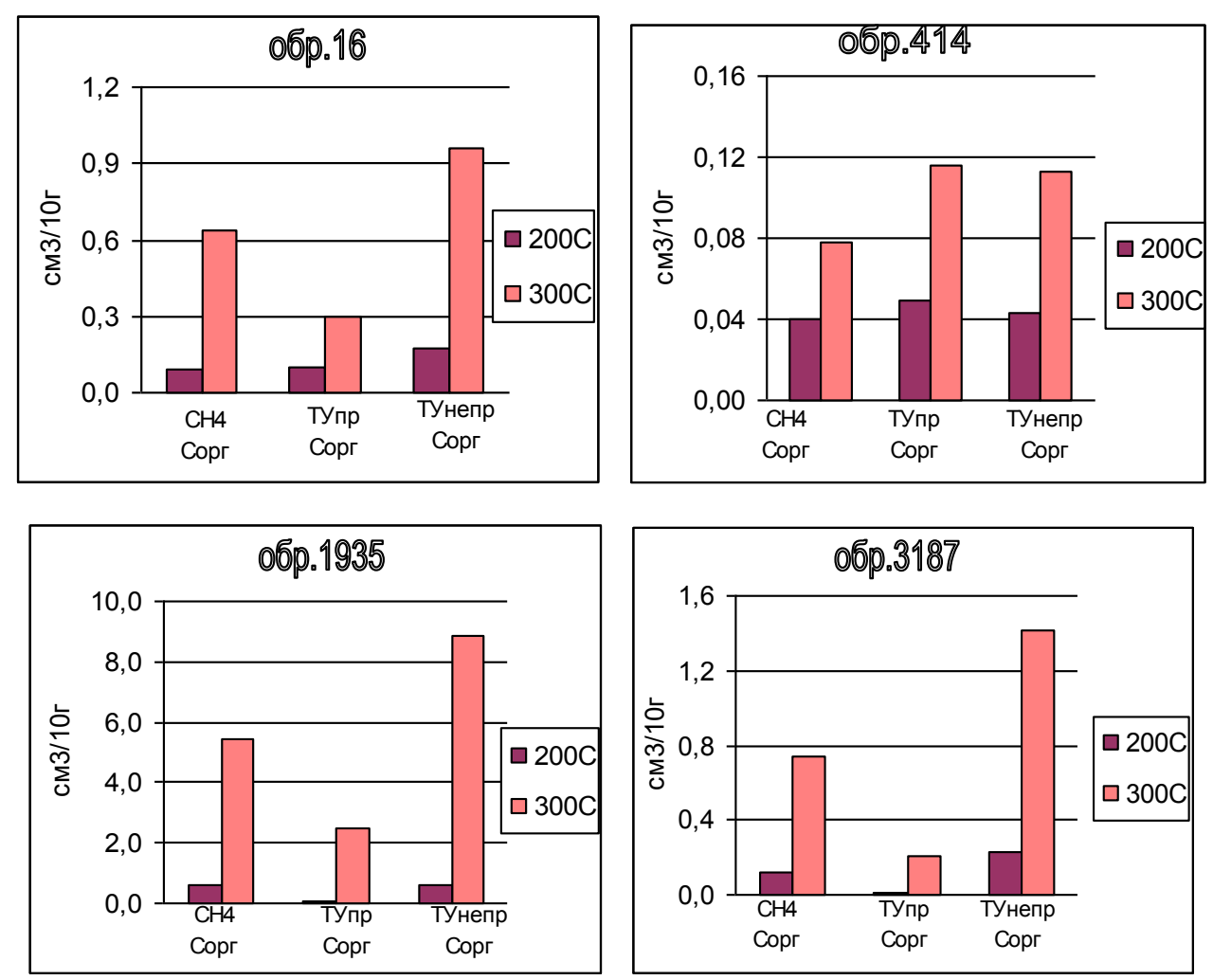

Рис. 2. Вариации основных газовых соотношений с Сорг при разных температурах, ${ }^{\circ} \mathrm{C}$

Тем самым проведенная работа подтвердила, что из приведенного диапазона температур для определения качественного и количественного состава газовой фазы наиболее оптимальной является температура $200^{\circ} \mathrm{C}$.

Вне зависимости от концентрации OB все образцы показали высокие или повышенные концентрации метана и его гомологов. Удивил образец 1926 (песчаник с углистыми включениями) тем, что на фоне низкого содержания
OB $(0,07 \%)$ в нём определено аномально высокое содержание УВ газов, что привело нас к заключению об удерживании этим образцом эпигенетичного газа (песчаник - хороший коллектор). На диаграмме отчетливо видна разница в составе газов, десорбированных из близкозалегающих образцов с приблизительно равными содержаниями Сорг и степенью катагенеза. Из этого следует, что, используя метод ТГХ, можно косвенно определять влияние эпигенетичного газа (рис. 3).

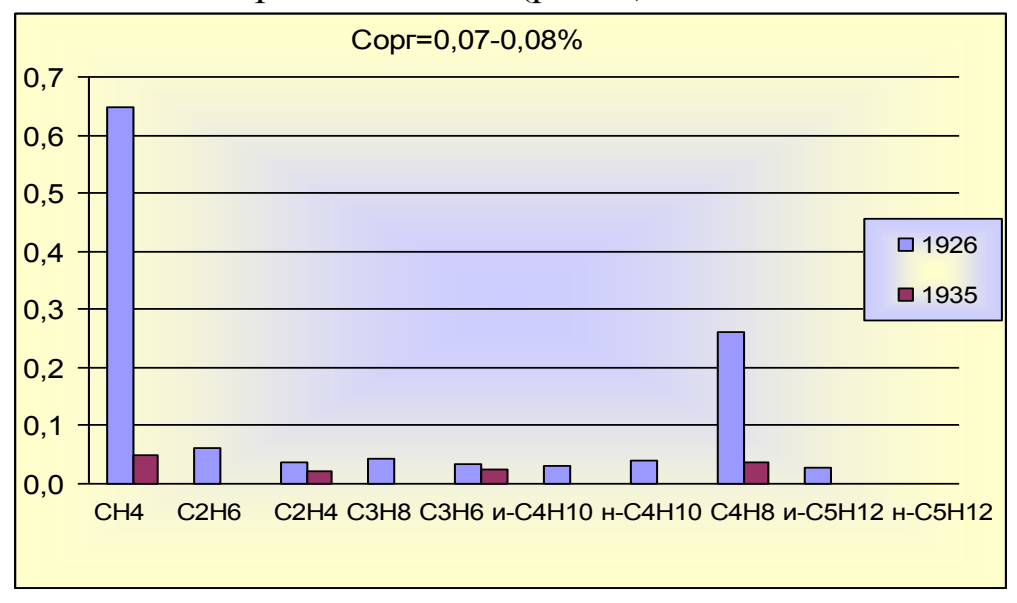

Рис. 3. Газы ТГХ в образиах 1935 и 1926 

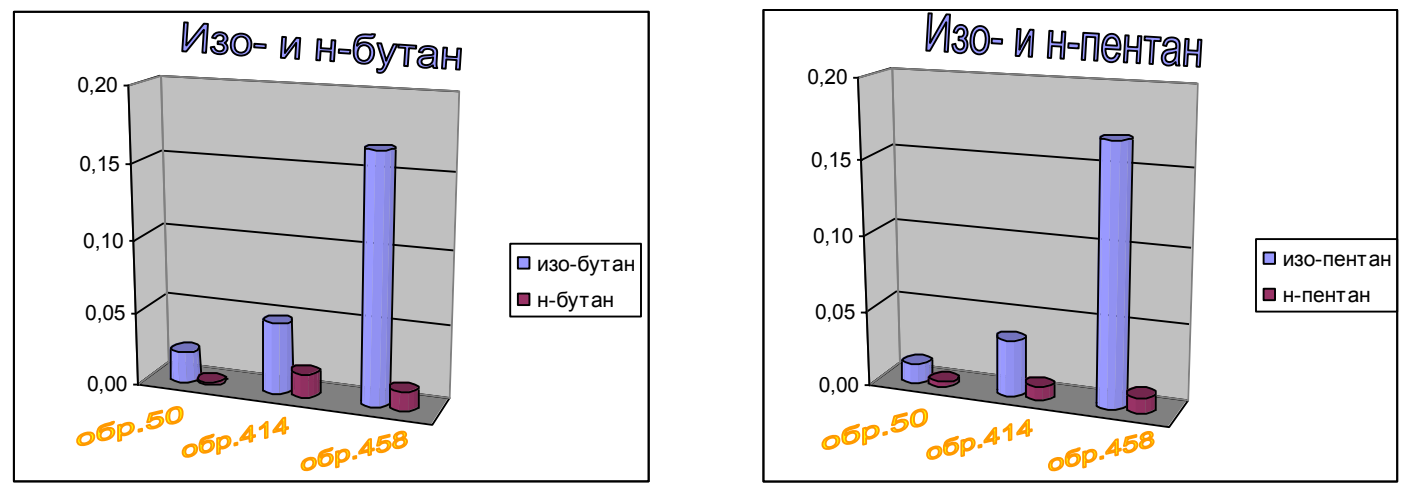

Рис. 4. Содержание изо и н-соединений в образиах 50, 414, 458

Другим примечательным фактом для нескольких образцов служит полученное в эксперименте превалирование в несколько раз газов изостроения над их гомологами нормального строения (рис. 4).

Известно, что под влиянием глинистых пород состав УВ газа в основном изменяется в сторону увеличения изомеров бутана и пентана. Таким образом, используя метод ТГХ, по составу газа можно уточнять влияние литологии.

Каждый этап катагенеза подчинен определенным закономерностям, связанным с изменением количества и качества углеводородов, выделяемых в процессе преобразования ОВ.
Рассмотрим таблицу значений соотношений метана, предельных и непредельных УВ к Сорг (табл. 2).

Из таблицы видно, что суммарное содержание метана и предельных УВ образца 16 доминирует над содержанием непредельных УВ, причем концентрация гомологов выше, чем метана, из чего можно предположить, что OB на данной глубине находится в ГЗН.

Далее по глубине фиксируется резкое понижение коэффициентов, что свидетельствует о перестройке структуры ОВ: УВ непредельные превалируют над суммой $\mathrm{CH}_{4}$ и ТУпредельного ряда.

Таблица 2. Величины отношений газовых компонентов к Сорг

\begin{tabular}{|c|c|c|c|c|c|c|}
\hline $\begin{array}{c}\text { Глубина, } \\
\text { м }\end{array}$ & $\begin{array}{l}\text { № об- } \\
\text { разца }\end{array}$ & \begin{tabular}{|c|}
$\mathrm{CH}_{4}$ \\
$/ \mathrm{Cop \Gamma}$ \\
$\mathrm{cm}^{3} / 10 \Gamma$ \\
\end{tabular} & $\begin{array}{l}\text { ТУпред } \\
/ \text { Сорг, } \\
\text { см }^{3} / 10 г\end{array}$ & \begin{tabular}{|c|} 
ТУнепред/ \\
Сорг, \\
см³/10г $^{3}$ \\
\end{tabular} & $\begin{array}{c}\mathrm{CH}_{4}+\mathrm{TУ}_{\text {пр }} \\
\mathbf{c m}^{3} / 10 \Gamma\end{array}$ & $\begin{array}{c}\text { Геохимическая информа- } \\
\text { тивность }\end{array}$ \\
\hline 3624,1 & 16 & 0,09 & 0,10 & 0,17 & 0,19 & $\left.\begin{array}{l}\left(\mathrm{CH}_{4}+\mathrm{TУ}_{п}\right)>\text { ТУнепр; } \\
\text { ТУпр>CН} 4\end{array}\right\}$ ГЗН \\
\hline 3969,62 & 414 & 0,03 & 0,03 & 0,063 & 0,060 & 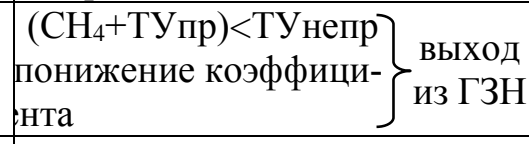 \\
\hline 5989,12 & $1926 \Pi$ & 9,27 & 1,36 & 3,92 & 10,63 & $\begin{array}{c}\text { Примесь эпигенетичного газа } \\
\text { искажает зависимость }\end{array}$ \\
\hline 5990,97 & 1935-н & 0,600 & 0,038 & 0,595 & 0,64 & 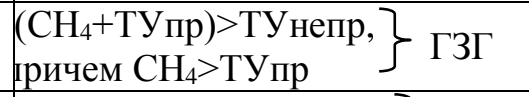 \\
\hline 6933,08 & $3187 \Pi$ & 0,12 & 0,01 & 0,23 & 0,13 & ТУнепр $>\left(\mathrm{CH}_{4}+\right.$ Тупр $)$ Выз ГЗГ \\
\hline
\end{tabular}

Примечание. ТУпр - тяжелые углеводороды предельного ряда; ТУнепр - тяжелые углеводороды непредельного ряда, ГЗН - главная зона нефтеобразования; ГЗГ - главная зона газообразования. 
В образце 1926П примесь эпигенетичного газа искажает зависимость от катагенеза.

В образце 1935н сумма метана и предельных УВ вновь превышает содержание УВ непредельного ряда, причем основная доля приходится на метан, что характерно для ГЗГ.

OВ базальта на высокой стадии катагенеза находится на ступени преобразования, свидетельствующей о выходе из ГЗГ.

Таким образом, закономерные изменения качественных и количественных показателей газовой фазы позволяют в какой-то мере косвенно судить о стадии катагенетического преобразования ОВ.

На основании всего вышесказанного можно сделать следующие выводы:

1) по суммарному содержанию УВГ можно выделить образцы с аномальными концентрациями для рассмотрения процессов их обогащения, в частности диагностировать примесь эпигенетичного га3a;

2) по составу газовой фазы можно уточнять влияние литологии;
3) закономерные изменения качественных и количественных показателей газовой фазы позволяют уточнить стадию катагенеза OB;

4) метод ТГХ в целом может быть использован для уточнения процессов генерации-сорбции-миграции путем сгущения сети опробования керна.

Это можно производить и после завершения бурения по керну, который лежит в кернохранилище, так как он не теряет со временем сильносвязанные газы и тем самым сохраняет информацию, необходимую для поисковых и разведочных работ.

Библиографический список

1. Старобинец И. С. Роль осадочных пород в распределении рассеянных углеводородных газов. М.: Недра,1976. 144 с.

2. Неручев С. Г. Газообразование при катагенезе органического вещества осадочных пород. Л.: Недра, 1983. 164 с.

3. Ермаков В. И., Зорькин Л. М., Скоробогатов В. А., Старосельский В. И. Геология и геохимия природных горючих газов. М.: Недра, 1990. 315 с.

\title{
Widening of informativeness of thermo gas chromatography method (according to the results of experimental work on core samples from the En-Yakhinskaya super deep borehole SG-7)
}

\author{
M.M. Belova \\ Joint Stock Company Kama Research Institute on Complex Deep and Superdeep \\ Borehole Investigations, 614016, Perm, Krasnoflotskaya St., 15. E-mail: \\ Kamniikigs@inbox.ru; info@ niikigs.ru
}

This article presents the results of studies of a deep sorbed gas, which were obtained during the experimental work. The analysis of gas from rock samples of EnYakhinskaya borehole was made using the method of thermo gas chromatography (TGC). Analyses are performed at three temperatures: 90, 200, 300 degrees Celsius. Generaliztion of the results of study allowed making conclusion that the method thermo gas chromatography has proven to be capable to establish the peculiarities of the process of gas generation. 
Key words: method thermo gas chromatography, sorbed gases, catagenesis, thermal decomposition, organic matter.

\section{References}

1. Starobinets I.S., 1976. Rol osadochnykh porod $\mathrm{v}$ raspredelenii rasseyanykh uglevodorodnykh gazov [Role of sedimentary rocks in distribution of the sparse hydrocarbon gases]. Moskva, Nedra.

2. Neruchev S.G., 1983. Gazoobrazovaniye pri katageneze organicheskogo vesh- chestva [Gas generation by catagenesis of organic matter]. Leningrad, Nedra.

3. Yermakov V.I., Zorkin L.M., Skorobogatov V.A., Staroselskiy V.I. 1990. Geologiya i geokhimiya prirodnykh goryuchikh gasov [Geology and geochemistry of natural combustible gases]. Moskva, Nedra.

Рецензент - доктор геолого-минералогических наук Т.В. Карасева 